\title{
XÂY DỰNG, HOÀN THIỆN BỘ KÝ HIỆU BẢN ĐỒ PHÂN LOẠI ĐẤT NGẬP NƯỚC NỘI ĐỊA Ở VIẸT NAM TRONG MÔI TRƯỜNG ARCGIS
}

\author{
NGUYẼ̃N THANH THỦY(1), LÊ LAN LAM(1), NHŨ VĂN KIÊN ${ }^{(1)}$, \\ NGUYẼ̃N TH!̣ HUẸ (1), NGUYẼ̃ TH! TRANG(1), TRẦN TUẤN ANH ${ }^{(2)}$ \\ (1) Viện Khoa học Đo đạc và Bản đồ \\ ${ }^{(2)}$ Cục Bản đồ - Bộ Tổng Tham mưu
}

\section{Tóm tắt:}

Bài báo giới thiệu quá trình xây dựng, hoàn thiện bộ ký hiệu cho bản đồ phân loại đất ngập nước nội địa trên môi trường ArcGIS nhằm hỗ trợ công tác thành lập bản đồ phân loại đất ngập nước một cách thống nhất ở Việt Nam. Bênh cạnh đó, với mã loại đất là sự kết hợp giưra mã quy định trong [2,7] sẽ hỗ trợ công tác xây dựng hồ sơ đề xuất công nhận các khu bảo tồn đất ngập nước Ramsar một cách thuận lợi.

\section{1. Đặt vấn đề}

Bản đồ phân loại đất ngập nước ở Việt Nam chủ yếu do các cơ quan nhà nước hoặc các cá nhân thành lập phục vụ mục đích nghiên cứu, giảng dạy. Tuy nhiên, do chưa có quy định về bộ ký hiệu riêng cho bản đồ phân loại đất ngập nước nên việc biên tập, trình bày bản đồ và xây dựng cơ sở dữ liệu liên quan chưa có sự thống nhất. Trong [6], Cục Viễn thám Quốc gia đã xây dựng bộ ký hiệu một số loại đất ngập nước theo công ước Ramsar có tính đến điều kiện Việt Nam gồm hệ đất ngập nước mặn, lợ (biển và ven biển) với 19 kiểu; 08 kiểu thuộc hệ đất ngập nước ngọt (nội địa) và một số yếu tố nền như đường ranh giới, giao thông, dân cư, bình độ,... trên phần mềm Microstation cho toàn bộ bản đồ dải đất ngập nước biển và ven biển Việt Nam. Dự án [8] đã xây dựng bộ ký hiệu trên phần mềm ArcGIS với 5 loại đất ngập nước ngọt tự nhiên thường xuyên, 5 loại đất ngập nước ngọt tự nhiên không thường xuyên, 5 loại đất ngập nước ngọt nhân tạo thường xuyên, bên cạnh đấy còn có 04 ký hiệu về phân khu chức năng, vùng lõi, vùng đệm khu bảo tồn; 16 ký hiệu yếu tố nền sử dụng bộ mã phân loại quy định trong [3]. Những ký hiệu này chưa đầy đủ và sẽ khó khăn cho việc quản lý, chuyển đổi dữ liệu cũng như trong công tác lập hồ sơ các khu Ramsar.

Nghiên cứu [5] đã xây dựng được thư viện với tổng số 90 ký hiệu cho bản đồ phân loại đất ngập nước, trong đó đối tượng chuyên đề đất ngập nước được xây dựng với bộ mã dựa trên các tài liệu [2,3]. Với bộ ký hiệu này có thể đáp ứng được công tác thành lập bản đồ phân loại đất ngập nước, tuy nhiên, bộ mã trong [3] chưa phải là hệ thống được ban hành chính thức. Chính vì vậy, ngày 22 tháng 8 năm 2016, để thống nhất trong công tác phân loại đất ngập nước, Tổng cục Môi trường đã ban hành quyết định 1093/QĐ-TCMT hướng dẫn kỹ thuật phân loại đất ngập nước [7], trong đó có 14 loại đất ngập nước ngọt tự nhiên và nhân tạo; quy định mã chuyển đổi giữa phân loại đất ngập nước ở Việt Nam và Ramsar. Đây là sự kế thừa, điều chỉnh của $[3,5]$, tuy nhiên trong số các loại đất ngập nước nội địa đã quy định trong quyết định này có 3 loại đất ngập nước chưa phân tách 
rõ mã tương ứng theo công ước Ramsar.

Với những thay đổi trong [7], cần thiết phải xây dựng, hoàn thiện bộ ký hiệu đất ngập nước nội địa đã được xây dựng trước đây [5] nhằm thống nhất cho công tác thành lập bản đồ, phục vụ quản lý đất ngập nước trong cả nước, trước mắt là dự án [9] do Viện Khoa học Đo đạc và Bản đồ đang triển khai.

\section{Phương pháp xây dựng bộ ký hiệu} cho bản đồ phân loại đất ngập nước nội địa trên môi trường ArcGIS

\subsection{Nguyên tắc thiết kế ký hiệu bản đồ}

Khi thiết kế, các ký hiệu bản đồ cần đảm bảo các nguyên tắc sau [4]:

- Cấu trúc của ký hiệu bản đồ: số lượng ký hiệu là ít nhất, đầy đủ nội dung, các ký hiệu có kích thước, cấu trúc không gian phù hợp, được thiết kế đơn giản, dễ vẽ, dễ định vị trên bản đồ...

- Mối tương quan giữa ký hiệu và đối tượng được thể hiện: đảm bảo tính đầy đủ, tính chặt chẽ khi thể hiện các đối tượng (hiện tượng) lên bản đồ cả về mặt chất lượng, số lượng.

- Mối tương quan giữa ký hiệu và người sử dụng: rõ ràng, dễ đọc, đảm bảo tính thống nhất trong một tổng thể và có khả năng nhận biết bằng mắt và bằng máy.

- Đảm bảo tính kế thừa: kế thừa các ký hiệu cho các loại bản đồ đã được quy định trong các quy phạm pháp luật..., nhằm đảm bảo tính thống nhất, tiết kiệm thời gian, giảm chi phí xây dựng hệ thống ký hiệu mới nhưng đồng thời phải đảm bảo tính thuận lợi trong khâu thiết kế, xây dựng cũng như phù hợp với tính năng của phần mềm tin học.

\subsection{Nguyên tắc hiển thị đối tượng bản đồ trên ArcGIS}

Tương tự các phần mềm GIS khác như Microstation, Mapinfo..., ArcGIS cũng hiển thị đối tượng với giá trị đo được tương ứng với kích thước thực của nó ngoài thực địa. Tuy nhiên, khác với Microstation thay vì nhập kích thước đối tượng thực theo từng tỷ lệ thì trong ArcGIS chỉ cần nhập đúng kích thước trên giấy sau in. Khi đó, ArcGIS tự động thay đổi kích thước đối tượng theo tỷ lệ làm việc. Do vậy, kích thước khi thiết kế ký hiệu trên ArcGIS là kích thước trên giấy sau in. Ví dụ, muốn ghi chú tên thành phố thuộc tỉnh VINH ở tỷ lệ 1:5.000 với kích thước trên giấy (sau in) là $20 \mathrm{~mm}$ thì trong hộp thoại Symbol Selector ta chỉ cần chọn kích thước (size) là 20 , sau đó hiển thị dữ liệu ở tỷ lệ 1:5.000 thì kích thước thực của nó là $100 \mathrm{~m}$, nếu hiển thị dữ liệu ở tỷ lệ $1: 10.000$ thì kích thước thực của nó sẽ thay đổi thành $200 \mathrm{~m}$.

\subsection{Tổ chức quản lý hệ thống ký hiệu bản đồ trên môi trường ArcGIS}

ArcGIS, cụ thể là ArcMap, cho phép thiết kế và quản lý hệ thống ký hiệu ở 4 dạng là điểm (Marker Symbol - MS), đường (Line Symbol - LS), vùng (Fill Symbol - FS), chũ̃ (Text Symbol) và được lưu trữ trong một thư viện mẫu (Style). Thư viện này cho phép thành lập bản đồ theo một chuẩn và tạo tính nhất quán trong các sản phẩm; cho phép thiết lập bản đồ mẫu tham chiếu cho tất cả các bản đồ còn bằng cách tham chiếu lớp *.Iyr cho các bản đồ [1]. Cụ thể như sau:

- Ký hiệu dạng điểm (MS) được sử dụng để thể hiện các đối tượng dạng điểm ArcGIS có 4 kiểu chuẩn ký hiệu đường chuẩn là Simple Marker Symbol (SMS); Character Marker Symbol (CMS): Arrow Marker Symbol (AMS); Picture Marker Symbol (PMS).

- Ký hiệu dạng đường (LS) được sử dụng để thể hiện các đối tượng dạng tuyến như mạng lưới giao thông, hệ thống nước, đường biên giới, phân vùng và các mạng lưới liên kết khác, gồm 4 loại chuẩn là Simple Line Symbol (SLS); Cartographic 
Line Symbol (CLS); Hash Line Symbol (HLS); Marker Line Symbol (MLS) và ký hiệu dạng ảnh - Picture Line Symbol (PLS).

- Ký hiệu dạng vùng (FS) được sử dụng để vẽ các đối tượng dạng vùng như các vùng quốc gia, tỉnh thành, các vùng sử dụng đất, các môi trường, các thửa đất và các dấu vết..., gồm có 5 loại: Simple Fill Symbol (SFS); Gradient Fill Symbol (GFS); Line Fill Symbol (LFS); Marker Fill Symbol (MFS); Picture Fill Symbol (PFS).

- Ký hiệu dạng chữ (TS) bao gồm nhãn (label), chú thích (annotation), tiêu đề (title), chữ động (dynamic text), miêu tả (description), ghi chú chỉ dẫn (callout), chú giải (legend), thước tỷ lệ, hiển thị nhãn mắt lưới, bảng biểu và các loại thông tin có liên quan.

\subsection{Thiết kế hệ thống ký hiệu bản đồ phân loại đất ngập nước trên ArcGIS}

Các ký hiệu được tham khảo và kế thừa từ nhiều nguồn khác nhau, trong đó chủ yếu từ nguồn bản đồ hiện trạng sử dụng đất, bản đồ địa hình và bản đồ đất ngập nước trong dự án [8] và nghiên cứu [5]. Đối với các loại đất ngập nước, nghiên cứu sẽ thiết lập mã loại đất sẽ là sự kết hợp giữa mã quy định trong tài liệu [7] - mã Ramsar [2].

Việc thiết kế ký hiệu được thực hiện trong chức năng Style Manager của ArcMap. Để thiết kế bộ ký hiệu bản đồ phân loại đất ngập nước cần phải tạo một thư viện trống để chứa các ký hiệu sẽ được thiết kế về sau. Bài báo này đã xây dựng bộ ký hiệu bản đồ đất ngập nước được quản lý trong thư viện BandoDNN.style.

Các bước thực hiện thiết kế ký hiệu bản đồ đất ngập nước trên ArcGIS bao gồm: (1) Truy cập vào thư viện BandoDNN.style ${ }^{\circledR}$ (2) Lựa chọn loại ký hiệu cần thiết kế ${ }^{\circledR}$ (3) Lựa chọn các ký hiệu thành phần, thiết lập tham số, thiết kế ký hiệu bằng hộp thoại Symbol Property Editor.

\section{Kết quả và thảo luận}

Nghiên cứu [5] đã thiết kế tổng số 90 ký hiệu của bản đồ phân loại đất ngập nước, có 64 ký hiệu được tạo mới, 26 ký hiệu được kế thừa và tham khảo từ bản đồ địa hình, bản đồ hiện trạng sử dụng đất về kích thước và cấu trúc ký hiệu. Bộ ký hiệu được tổ chức thành 3 nhóm: đối tượng trình bày, đối tượng nền địa lý và đối tượng chuyên đề đất ngập nước. Nhóm đối tượng đất ngập nước được thiết kế dựa trên các tài liệu [2,3,8] gồm 22 ký hiệu, trong đó có 18 loại đất với mã được hình thành từ mã của $[2,3]$. Tuy nhiên, trong quy định [7] đã có nhiều điều chỉnh về tên gọi, mã loại đất, vì vậy, bộ ký hiệu cũng cần được thiết kế lại theo quy định mới.

Do các yếu tố trình bày và yếu tố nền không đổi, để tiếp tục hoàn thiện bộ ký hiệu đã được thực hiện trước đó, trong nghiên cứu này chỉ thiết kế lại ký hiệu cho các loại đất ngập nước. Cụ thể, từ 14 loại đất ngập nước quy định trong [7] đã được tách và thiết kế thành 17 ký hiệu phù hợp với mã Ramsar [2]. Như vậy, bộ ký hiệu mới đã giảm đi 01 đối tượng do đất "Đầm, bãi lầy, đồng cỏ, lác/lách” trong [3] đã được bỏ khỏi quy định [7].

Kết quả thiết kế các đối tượng chuyên đề đất ngập nước được trình bày trong Bảng 1 .

\section{Kết luận}

Như vậy, với việc điều chỉnh lại các ký kiệu chuyên đề đất ngập nước đã cập nhật, hoàn thiện lại bộ ký hiệu bản đồ đất ngập nước nội địa, với mã các loại đất ngập nước nội địa được cấu thành từ mã do Tổng cục Môi trường quy định và mã Ramsar sẽ đảm bảo cho việc việc trình bày, thành lập bản đồ đất ngập nước được thống nhất, nhanh chóng từ cơ sở dữ liệu; hỗ trợ trong công tác quản lý và lập hồ sơ đề nghị công nhận khu bảo tồn đất ngập nước thuận lợi hơn, giúp người đọc bản đồ có thể xác định được đồng thời theo hai mã phân loại quốc tế và Việt Nam.O 
Bảng 1: Hệ thống ký hiệu đối tượng chuyên đề cho bản đồ phân loại đất ngập nước nội địa tỷ lệ 1:5.000 và 1:10.000 được thiết kế trong ArcGIS

\begin{tabular}{|c|c|c|c|c|c|c|}
\hline TT & Tên đối tượng & $\begin{array}{l}\text { Loại đối } \\
\text { tượng }\end{array}$ & Tên ký hiệu & $\begin{array}{c}\text { Ký hiệu (Pt) } \\
\text { 1:5.000, 1:10.000 }\end{array}$ & $\begin{array}{l}\text { Loại ký hiệu } \\
\text { cấu thành }\end{array}$ & Ghi chú \\
\hline 1 & \multicolumn{6}{|c|}{ Đất ngập nước ngọt tự nhiên thường xuyên } \\
\hline 1 & $\begin{array}{l}\text { Sông, suối có nước thường } \\
\text { xuyên }\end{array}$ & Fill & Stx-M & Stz-M & 1SFS & Tạo mới \\
\hline 2 & Hồ tự nhiên ( $\geq 8$ ha) & Fill & $\mathrm{Htn}-\mathrm{O}$ & HinO O & 1SFS & Tạo mới, tách \\
\hline 3 & Hồ tự nhiên (< 8 ha) & Fill & Htn-P & $F m-F$ & 1SFS & Tạo mới, tách \\
\hline 4 & $\begin{array}{l}\text { Suối, điểm nước khoáng, } \\
\text { nước nóng) }\end{array}$ & Fill & Snn-Y & $\therefore \operatorname{Snn}=\hat{Z g}$. & $\begin{array}{l}1 \text { SFS } \\
2 \mathrm{MFS}\end{array}$ & Tạo mới \\
\hline II & \multicolumn{6}{|c|}{ Đất ngập nước ngọt tự nhiên không thường xuyên } \\
\hline 5 & Suối có nước theo mùa & Fill & Stm-N & $\mathrm{Stm}-\mathrm{N}$ & 1SFS & Tạo mới \\
\hline 6 & $\begin{array}{l}\text { Vùng đất than bùn không có } \\
\text { rừng (các đầm lầy có cây } \\
\text { bụi) }\end{array}$ & Fill & Tb-U & & $\begin{array}{l}1 \mathrm{SFS} \\
2 \mathrm{MFS}\end{array}$ & Tạo mới, tách \\
\hline 7 & $\begin{array}{l}\text { Vùng đất than bùn có rừng } \\
\text { (vùng đầm lầy có rừng) }\end{array}$ & Fill & $\mathrm{Tb}-\mathrm{Xp}$ & $\begin{array}{l}---- \\
--\overline{-T b-X_{1}} \\
----\overline{-}\end{array}$ & $\begin{array}{l}1 \mathrm{SFS} \\
2 \mathrm{MFS}\end{array}$ & Tạo mới, tách \\
\hline 8 & $\begin{array}{l}\text { Vùng ngập nước có cây bụi } \\
\text { chiếm ưu thế và ngập nước } \\
\text { theo mùa }\end{array}$ & Fill & $\mathrm{Cb}-\mathrm{W}$ & $\mathrm{Cb}-\mathrm{W}$ & 1SFS & Tạo mới \\
\hline 9 & $\begin{array}{l}\text { Vùng ngập nước có cây gỗ } \\
\text { chiếm ưu thế và ngập nước } \\
\text { theo mùa }\end{array}$ & Fill & $\mathrm{Cg}-\mathrm{Xf}$ & $\mathrm{Cg}-\mathrm{Xf}$ & 1SFS & Tạo mới \\
\hline 10 & $\begin{array}{l}\text { Hệ thống thuỷ văn ngầm } \\
\text { các-xtơ và hàng, động nội } \\
\text { địa }\end{array}$ & Fill & Cnd-Zk(b) & 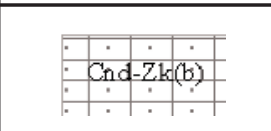 & $\begin{array}{l}1 \mathrm{SFS} \\
2 \mathrm{LFS} \\
1 \mathrm{MFS}\end{array}$ & Tạo mới \\
\hline III & \multicolumn{6}{|l|}{ Đất ngập nước nhân tạo } \\
\hline 11 & $\begin{array}{l}\text { Ao, hồ, đầm nuôi trồng thuỷ } \\
\text { sản nước ngọt ( } \geq 8 \text { ha) }\end{array}$ & Fill & Ann-1 & Ann-1 & $\begin{array}{l}1 \text { SFS } \\
1 \mathrm{LFS}\end{array}$ & Tạo mới, tách \\
\hline 12 & $\begin{array}{l}\text { Ao, hồ, đầm nuôi trồng thuỷ } \\
\text { sản nước ngọt (< } 8 \text { ha) }\end{array}$ & Fill & Ann-2 & Ann-2 & 1SFS & Tạo mới, tách \\
\hline 13 & $\begin{array}{l}\text { Sông đào, kênh, mương, } \\
\text { rạch }\end{array}$ & Fill & Sd-9 & Sd-9 & 1SFS & Tạo mới \\
\hline 14 & $\begin{array}{l}\text { Hồ chứa nước nhân tạo (>8 } \\
\text { ha) }\end{array}$ & Fill & Hnt-6 & Hnt-6 & 1SFS & Tạo mới \\
\hline 15 & $\begin{array}{l}\text { Ao, hồ chứa và xử lý nước } \\
\text { thải }\end{array}$ & Fill & Vxl-8 & $\sim \tilde{\operatorname{Vxl}} \sim$ & $\begin{array}{l}1 \mathrm{SFS} \\
1 \mathrm{MFS}\end{array}$ & Tạo mới \\
\hline 16 & Đất canh tác nông nghiệp & Fill & Dnn-3 & Dnn-3 & 1SFS & Tạo mới \\
\hline 17 & $\begin{array}{l}\text { Moong khai thác khoáng } \\
\text { sản }\end{array}$ & Fill & Mkt-7 & $\begin{array}{c}\mathrm{Mks-7} \\
\mathbf{4}\end{array}$ & $\begin{array}{l}1 \mathrm{SFS} \\
1 \mathrm{MFS} \\
\end{array}$ & Tạo mới \\
\hline
\end{tabular}


Tài liệu tham khảo

[1]. Esri ArcGIS Help 10.1. Symbols and Styles.

http://resources.arcgis.com 20h:30' date 20-6-2013.

[2]. Ramsar Convention Secretariat. Information Sheet on Ramsar Wetlands (RIS) 2009-2014 version. Download from www.ramsar.org:pdf:ris:key_ris_e.pdf, 2013.

[3]. Bộ Tài nguyên và Môi trường. Dự thảo số 3 Thông tư Quy định hệ thống phân loại đất ngập nước Việt Nam. Hà Nội, 2009.

[4]. Trần Trung Hồng. Trình bày và chuẩn bị in bản đồ (bài giảng cao học ngành bản đồ). Hà Nội, 2000.

[5]. Nhữ Văn Kiên, Nguyễn Thanh Thủy. Nghiên cứu xây dựng quy trình thành lập và bộ ký hiệu cho bản đồ phân loại đất ngập nước. Viện Khoa học Đo đạc và Bản đồ, Hà Nội, 2013.
[6]. Tổng cục Môi trường. Điều tra, đánh giá tình hình quy hoạch, kế hoạch sư dụng đất ngập nước ven biển và đề xuất phương hướng quy hoạch sử dụng nhằm bảo vệ môi trường và phòng chống thiên tai. Hà Nội, 2011.

[7]. Tổng cục Môi trường. Ban hành hướng dẫn kỹ thuật phân loại đất ngập nước. Quyết định 1093/QĐ-TCMT ngày 22 tháng 8 năm 2016. Hà Nội, 2016

[8]. Viện Khoa học Đo đạc và Bản đồ. Khảo sát, đo đạc thành lập các loại bản đồ phục vụ khoanh vùng bảo tồn và phát triển bền vững vùng đất ngập nước Đồng Tháp Mười. Hà Nội, 2012.

[9]. Viện Khoa học Đo đạc và Bản đồ. Khảo sát, đo đạc, thành lập các loại bản đồ phục vụ khoanh vùng bảo tồn và phát triển bền vững vùng đất ngập nước bán đảo Cà Mau. Hà Nội, 2015 - 2017.0

\section{Summary}

\section{Building and completing the style library for inland wetland mapping in Vietnam in the ArcGIS software}

Nguyen Thanh Thuy, Le Lan Lam, Nhu Van Kien, Nguyen Thi Hue, Nguyen Thi Trang,

Vietnam Institute of Geodesy and Cartography

\section{Tran Tuan Anh}

\section{Defense Mapping Agency of Vietnam, Ministry of Defense}

This paper introduces about designing and making style library of inland wetland classification map in the ArcGIS software. That library support to establish wetland map and representation of wetland database in Vietnam. Besides that, base on the combination of Vietnam Environment Administration (VEA) and Ramsar codes, it will support to make proposed documents to be accepted the Ramsar sites for wetland conservation easier. $O$ 